\title{
Philosophiques
}

\section{Réponse à Yvon Gauthier}

\section{Pierre Raymond}

Volume 5, numéro 1, avril 1978

URI : https://id.erudit.org/iderudit/203093ar

DOI : https://doi.org/10.7202/203093ar

Aller au sommaire du numéro

Éditeur(s)

Société de philosophie du Québec

ISSN

0316-2923 (imprimé)

1492-1391 (numérique)

Découvrir la revue

Citer ce document

Raymond, P. (1978). Réponse à Yvon Gauthier. Philosophiques, 5(1), 189-191.

https://doi.org/10.7202/203093ar

Ce document est protégé par la loi sur le droit d'auteur. L'utilisation des services d'Érudit (y compris la reproduction) est assujettie à sa politique d'utilisation que vous pouvez consulter en ligne.

https://apropos.erudit.org/fr/usagers/politique-dutilisation/
Cet article est diffusé et préservé par Érudit.

Érudit est un consortium interuniversitaire sans but lucratif composé de l’Université de Montréal, l'Université Laval et l'Université du Québec à Montréal. Il a pour mission la promotion et la valorisation de la recherche. https://www.erudit.org/fr/ 


\title{
RÉPONSE À YVON GAUTHIER
}

\author{
par Pierre Raymond
}

À propos de l'article de M. Gauthier, "L'épistémologie française des mathématiques", publié dans Critique de janvier 1978, et, plus particulièrement, à propos de la section 6, "Une théorie matérialiste des mathématiques ", qui me concerne, je tiens à signaler ce qui suit.

1. Les trois seules allusions à mon livre Le passage au matérialisme constituent autant d'erreurs faciles à manifester.

- Que la notion de fondements (des mathématiques) soit liée à l'activité (philosophique et idéaliste) de fondation, que le théorème de Gödel sur les preuves de non-contradiction fasse s'écrouler la problématique du fondement, et que cet écroulement ait un effet majeur sur l'aspect philosophique de cette entreprise : autant de thèses centrales de Cavaillès, citées par moi selon son vocabulaire, et qui sont la texture même de Métbode axiomatique et formalisme et de Sur la logique et la théorie de la science. Thèses que je reprends à mon compte (dangers d'un fonctionnement et d'une exploitation idéalistes de la problématique du fondement, sans aucune identification, de ma part, du travail logicien et de l'activité philosophique), en disant d'où elles viennent.

M. Gauthier, lui, ne cite pas Cavaillès. $\AA$ mon propos, il dit, p. 29, que l'auteur de ces thèses " ne mérite pas la peine d'une réfutation ". Mais, à propos de Cavaillès, il dit, p. 10 : "sa philosophie mathématique, qui savait se tenir près des mathématiques, demeure pertinente et peut inspirer l'épistémologie contemporaine ou le philosophe instruit de savoir actuel."

Ces thèses mériteṇt la discussion, c'est évident. Elles ont été déjà discutées, rejetées par certains, je le sais. La discussion implique bien sûr qu'on se soucie de définir aussi l'activité philoso- 
phique de fondation et les modalités de son intériorisation masquée par la logique. Un logicien n'est pas forcément le plus habilité pour le faire.

Mais M. Gauthier, lui, ne tente rien de tout cela. Son allusion au travail de Gödel, entre 1939 et 1958, sur l'éventualité de "fondements platoniciens", est ici dénuée de portée.

- La phrase "absurde" et digne d'un " journaliste du Figaro " que $M$. Gauthier cite sur le concept de " forcing " est une allusion à une entreprise de M.-A. Sinaceur (Critique, janvier 1973) pour passer de la logique mathématique à la philosophie; je la cite moi-même pour la critiquer (sans la traiter comme M. Gauthier le fait). On admirera les talents de lecteur de ce logicien, et le poids de cet exemple qui devrait être le meilleur d'une liste " fastidieuse ", puisqu'il est le seul.

- La volonté de " m'en tenir " à un discours sur les discours philosophiques sur les mathématiques qu'il me prête, et l'interprétation hâtive qu'il en donne, sont des contresens, qui ne valent en effet pas la réfutation. Il suffit de me lire.

2. Le contexte de ces allusions ne peut m'inciter à aucune autre réponse : il ne s'agit que d'opinions vagues, sans arguments et entrecoupées de petites insultes.

Le reste de l'article, souvent du même genre, ne me concerne pas. Cavaillès ne pourra pas se justifier de s'être limité à la théorie des ensembles: il a sans doute eu tort, - pour M. Gauthier, le juge universel, - d'être exécuté trop tôt par les Allemands. Les auteurs vivants pris à parti réagiront comme ils l'entendront. Je relève toutefois que les rapports des informations scientifiques avec leurs thèses philosophiques ne sont que rarement compris par $M$. Gauthier. Les informations distinctes et les objections qu'il leur apporte n'atteignent dont pas en général leur cible. Il ne suffit pas de se prétendre philosophe pour l'être.

Quant à ses affirmations, rares, qu'il dit philosophiques, je ne saurais vraiment pas y répondre : ce sont des banalités logiciennes en deçà de la philosophie. Et j'ignore ce qu'est un philosophe " marxiste comme tout le monde" (p. 30).

Je signale enfin que cet article, daté d'août 1977, a déjà été publié tel quel, pour une partie, dans la revue canadienne Dialo- 
gue, en novembre 1975. M. Gauthier en a simplement ôté la dernière phrase, qui mérite d'être citée : "Pour ma part, j'indiquerai les grandes lignes d'un constructivisme matérialiste dans un ouvrage prochain qui viendra à son heure. "Le but de M. Gauthier, dans ce règlement de comptes brouillon, apparaissait déjà clairement : il croyait, et croit encore ne pouvoir faire de publicité à son œuvre décisive que par ce procédé négatif.

Ne pas retoucher cet article entre-temps permettait à $M$. Gauthier d'ignorer d'autres ouvrages écrits depuis sur la logique ou sur les mathématiques.

Ou de feindre de les ignorer, puisqu'il cite avec faveur et utilise même abondamment (p. 23) Philosopbie et calcul de l'infini, en oubliant seulement de mentionner que j'en suis l'auteur d'à peu près la moitié.

Ces remarques à propos de l'article de $\mathrm{M}$. Gauthier ne concernent que les rapports de sa position de logicien avec la philosophie. Rapports caractérisés par l'ignorance de ce qu'est la philosophie, par la morgue logicienne du "le reste n'est que métaphysique ". Les rapports de ce même impérialisme de logicien avec les mathématiques sont une autre question que nous n'avons pas la prétention de traiter. Des mathématiciens ont aussi matière à réagir. 